Article

\title{
Evaluation of Anti-Aging Performance of Biochar Modified Asphalt Binder
}

\author{
Wenhao Dong ${ }^{1}$, Feng Ma ${ }^{1}$, Chen $\mathrm{Li}^{1}$, Zhen Fu ${ }^{2, *}$, Yue Huang ${ }^{3}$ and Jenny Liu ${ }^{4}$ \\ 1 School of Highway, Chang'an University, Xi'an 710064, China; dongwenhao@chd.edu.cn (W.D.); \\ mafeng@chd.edu.cn (F.M.); 2018121140@chd.edu.cn (C.L.) \\ 2 School of Material and Science Engineering, Chang'an University, Xi'an 710064, China \\ 3 Institute for Transport Studies, University of Leeds, Leeds LS2 9JT, UK; y.huang1@leeds.ac.uk \\ 4 Department of Civil, Architectural and Environmental Engineering, Missouri University of Science and \\ Technology, Rolla, MO 65401, USA; jennyliu@mst.edu \\ * Correspondence: zhenfu@chd.edu.cn; Tel.: +86-158-2993-9583
}

Received: 29 September 2020; Accepted: 22 October 2020; Published: 28 October 2020

\begin{abstract}
As a renewable biomass resource, biochar is new to modify or replace asphalt binder in pavement engineering. This paper focuses on the effect of biochar on the anti-aging performance of asphalt binder. The short- and long-term aging properties of biochar modified asphalt binder were investigated using dynamic shear rheometer (DSR) and bending beam rheometer (BBR) tests. The modification mechanism was investigated through the Fourier-transform infrared spectroscopy (FTIR) test. The aging tests and viscosity analysis showed that the softening point of biochar modified asphalt binder was higher than base asphalt binder, while the aging index and aging viscosity ratio were lower than base asphalt binder. After aging, the temperature sensitivity of biochar modified asphalt binder decreased and the high-temperature stability, reflected by dynamic shear modulus and resistance to rutting, improved. The BBR test after long-term aging showed that the anti-aging performance of biochar modified asphalt binder decreased with the decrease in temperature, and control of the biochar content could ensure good low-temperature performance of the modified asphalt binder after aging. FTIR spectra analysis showed that biochar in modified asphalt binder is physically blended with asphalt binder.
\end{abstract}

Keywords: pavement material; modified asphalt binder; biochar; aging performance; rheology

\section{Introduction}

The environmental sustainability of the use of asphalt binder in pavement engineering is receiving more and more attention [1-4]. On one hand, the imbalance between supply and demand of petroleum asphalt binder endangers a sustainable supply for asphalt pavement construction and maintenance. On the other hand, road asphalt binder generates a large amount of greenhouse gases during the production process. Biomass resources have the advantages of low embodied carbon and being renewable $[5,6]$. They can be used to partially replace petroleum asphalt binder or as a modifier to improve the performance of asphalt binder [7]. They can also help to enhance asphalt binder durability and therefore reduce maintenance needs as well as greenhouse gas emissions and construction costs $[8,9]$.

Through the pyrolysis process, biomass can be decomposed into gases, liquids (biomass oil) and solid (biochar) products $[10,11]$. Biochar is a common renewable biomass resource. It mainly includes charcoal, bamboo charcoal and straw charcoal, etc. Its main components are carbon and aromatic hydrocarbons, and it also contains nitrogen $(\mathrm{N})$, oxygen $(\mathrm{O})$, hydrogen $(\mathrm{H})$, sulfur $(\mathrm{S})$ and a small amount of trace elements. Biochar has a highly porous (carboxylic esterification and aromatization) 
structure with a large specific surface area and low solubility [12]. With its unique physical and chemical properties, it can be used as a modifier for petroleum asphalt binder, which has a significant effect on the pavement performance.

As a bio-renewable resource, biochar has been widely used in the agriculture sector. It can absorb pesticides and heavy metals in the soil and thus reduce soil and groundwater pollution and address other issues such as agricultural and forestry waste and greenhouse gas emissions $[13,14]$. Previous studies on carbon-based asphalt binder modifiers have shown that carbonaceous materials such as biochar exhibit good compatibility with asphalt binder [15]. Walters added nanoclay and biochar produced from pig manure into asphalt binder, and results show that biochar could improve the dispersion of nanoclay in asphalt binder and thereby the oxidation resistance of asphalt binder [16]. Chebil et al. found that the charcoal produced by wood pyrolysis as a modifier could effectively slow down the oxidation of asphalt binder components, indicating that charcoal had an effect on slowing asphalt binder aging [17]. Zhang et al. also found that the incorporation of biochar into asphalt binder could hinder the aging of binder [18], which was consistent with Chebil's conclusion. Biochar modified asphalt binder was also found to have better rutting resistance than carbon fiber modified asphalt binder [19]. Fu et al. reviewed the properties of biochar modified asphalt binder and its mixture, and they found that adding biochar into asphalt binder could reduce the temperature sensitivity of asphalt binder [20].

Previous studies on biochar modified asphalt binder have shown that biochar can improve the performance of asphalt binder. However, there is no systematic analysis of its effect on the anti-aging performance of asphalt binder, as oxidative aging is an inevitable process in practical road paving and significantly affects the performance and service life of asphalt binder [21-25]. A comprehensive study was therefore conducted to investigate the properties of modified asphalt binder with different biochar contents under different aging conditions. The objectives of this study are to (1) investigate the anti-aging performance of biochar modified asphalt binder, and (2) analyze the high- and low-temperature rheological properties of a variety of biochar modified binders after short- and long-term aging.

\section{Materials and Experimental Design}

\subsection{Materials}

The base asphalt binder used in this study was an asphalt binder with a penetration grade of $70\left(70^{\#}\right)$. Table 1 provides the basic properties of the asphalt binder. The DS-510F biochar was used, which had a powdery appearance. Table 2 lists the technical parameters of the biochar used in this study. Figure 1 presents the scanning electron microscopy (SEM) images of biochar particles at different magnifications. In this paper, biochar and base asphalt binder were mixed by using a high-speed shear mixer for $45 \mathrm{~min}$ at $145^{\circ} \mathrm{C}$. The biochar modified binders were prepared with six different blending contents, i.e., $0,5,7.5,10,12.5$, and $15 \%$, by weight of asphalt binder.

\subsection{Aging Procedure}

Biochar modified and base binders were both aged by thin film oven test (ASTM D1754) and pressure aging vessel (PAV) (ASTM D6521) [26,27]. The thin film oven test was chosen to simulate the short-term aging that occurs during production of asphalt concrete. The PAV was used to simulate the long-term (oxidative) aging of asphalt binder that occurs during pavement service life. Residues from the PAV test are used to estimate the physical or chemical properties of an asphalt binder after 5 to 10 years in the field. The aged asphalt binder was tested for penetration and rheological properties, and the results were compared with those of virgin asphalt binder. 
Table 1. Technical properties of base asphalt binder $70^{\#}$.

\begin{tabular}{|c|c|c|c|}
\hline \multicolumn{2}{|c|}{ Property } & Test Results & Technical Requirements \\
\hline \multicolumn{2}{|c|}{ Penetration $\left(25^{\circ} \mathrm{C}, 100 \mathrm{~g}, 5 \mathrm{~s}\right)(0.1 \mathrm{~mm})$} & 63 & $60-80$ \\
\hline \multicolumn{2}{|c|}{ Ductility at $15^{\circ} \mathrm{C}(\mathrm{cm})$} & 103 & $\geq 100$ \\
\hline \multicolumn{2}{|c|}{ Ductility at $10^{\circ} \mathrm{C}(\mathrm{cm})$} & 30 & $\geq 20$ \\
\hline \multicolumn{2}{|c|}{ Softening point $\left({ }^{\circ} \mathrm{C}\right)$} & 48 & $\geq 43$ \\
\hline \multicolumn{2}{|c|}{ Flashpoint $(\mathrm{COC})\left({ }^{\circ} \mathrm{C}\right)$} & 280 & $\geq 260$ \\
\hline \multicolumn{2}{|c|}{ Paraffin content (distillation method) (\%) } & 1.8 & $\leq 2.2$ \\
\hline \multicolumn{2}{|c|}{ Density $\left(15^{\circ} \mathrm{C}\right)\left(\mathrm{g} / \mathrm{cm}^{3}\right)$} & 0.97 & measured value \\
\hline \multicolumn{2}{|c|}{ Solubility $(\%)$} & 99.7 & $\geq 99.5$ \\
\hline \multirow{3}{*}{ Thin film oven test $\left(163^{\circ} \mathrm{C}, 5 \mathrm{~h}\right)$} & Mass loss $(\%)$ & 0.02 & $\leq \pm 0.8$ \\
\hline & Residual penetration ratio (\%) & 62.7 & $\geq 54$ \\
\hline & Residual ductility $\left(10^{\circ} \mathrm{C}\right)(\mathrm{cm})$ & 14 & $\geq 4$ \\
\hline
\end{tabular}

Table 2. Biochar technical parameters.

\begin{tabular}{ccccccc}
\hline Item & Particle Size (mesh) & $\mathrm{pH}$ & Specific Surface Area $\left(\mathrm{m}^{2} / \mathrm{g}\right)$ & Saturate $(\%)$ & Carbon Content $(\%)$ & Iron Content $(\%)$ \\
\hline Biochar & 150 & $>7$ & $>400$ & $<10$ & $>90$ & $<0.1$ \\
\hline
\end{tabular}

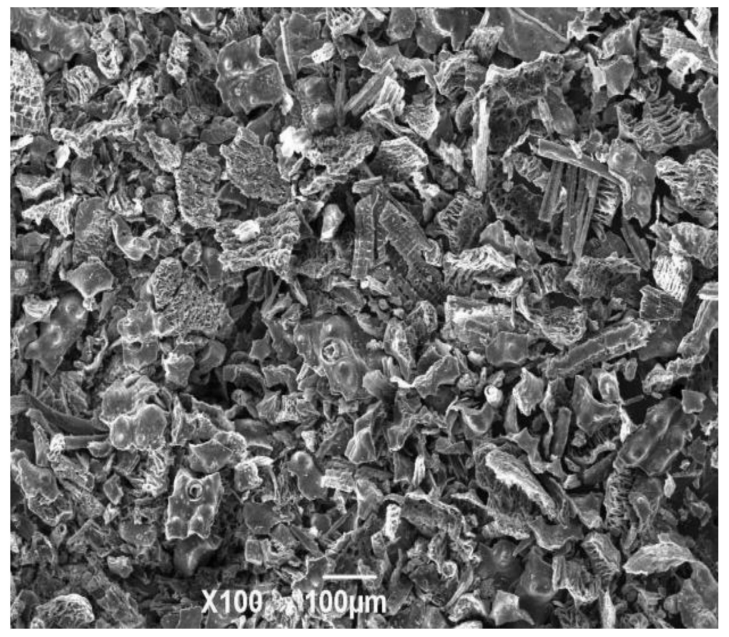

(a)

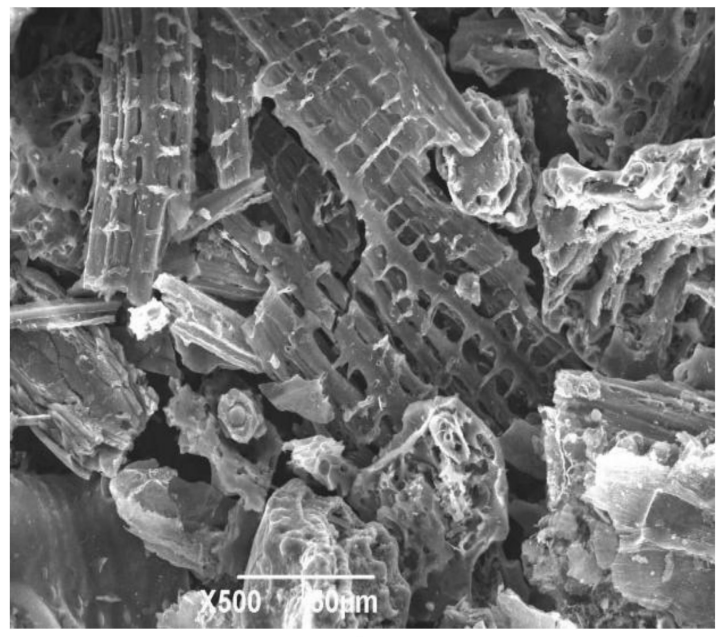

(b)

Figure 1. Biochar particles with different amplification ratios: $(\mathbf{a}) \times 100 ;(\mathbf{b}) \times 500$.

\subsection{Physical Properties}

The physical properties of asphalt binder, including mass loss, softening point, aging index and viscosity ratio, were used to evaluate the effect of biochar. Three parallel tests are conducted for each physical property test, and the average value of the three measured values is taken as the test result. The allowable error of the parallel test meets the requirements of Chinese industry standards (JTG E20-2011) to ensure the reliability of test [28]. The aging of asphalt binder is usually indicated by the changes in viscosity, since asphalt binder is a material with rheological properties and its viscosity increases after aging. Therefore, the aging of the asphalt binder can be measured by measuring the change in viscosity before and after aging [29]. The smaller the viscosity ratio, the better the anti-aging performance of the asphalt binder. The aging index $C$ of asphalt binder is also used to evaluate the anti-aging performance of asphalt binder. The smaller the $C$ value, the better the aging resistance of the asphalt binder. The aging index $C$ and the asphalt binder viscosity ratio $\left(K_{\eta}\right)$ can be calculated by Equations (1) and (2), respectively [28].

$$
C=\lg \lg \left(\eta_{2} \times 10^{3}\right)-\lg \lg \left(\eta_{1} \times 10^{3}\right)
$$




$$
\mathrm{K}_{\eta}=\frac{\eta_{2}}{\eta_{1}}
$$

where,

$\mathrm{C}=$ aging index,

$\eta_{1}=$ the dynamic viscosity of asphalt binder before aging at $60^{\circ} \mathrm{C}(\mathrm{Pa} \cdot \mathrm{s})$,

$\eta_{2}=$ the dynamic viscosity of asphalt binder after aging at $60^{\circ} \mathrm{C}(\mathrm{Pa} \cdot \mathrm{s})$,

$\mathrm{K}_{\eta}=$ viscosity ratio.

\subsection{Dynamic Mechanical Analysis}

Dynamic mechanical analysis was performed using a dynamic shear rheometer (DSR). The frequency scanning was performed on aged asphalt binder to construct its dynamic shear modulus and phase angle master curve and to analyze the phase structure, high temperature performance and temperature sensitivity of the modified asphalt binder after aging. The frequency scanning ranged from $0.1 \%$ to $100 \%$, and the applied strain was $3 \%$. Temperature scanning tests for six types of asphalt binder were conducted at seven temperatures: $40,46,52,58,64,70$ and $76{ }^{\circ} \mathrm{C}$. The frequency was $10 \mathrm{rad} / \mathrm{s}$, and the applied strain was $3 \%$.

In the temperature scanning test, the rheological indicators used in the study included shear modulus, phase angle, viscosity-temperature susceptibility (VTS) and rutting factors $\left(G^{*} / \sin \delta\right)$. The viscosity-temperature susceptibility is a commonly used indicator to measure the temperature sensitivity of asphalt binder, which decreases after aging. Based on the results from DSR temperature scanning tests, the equivalent viscosity of asphalt binder can be calculated by Equation (3) according to the Cox-Merz dynamic and static viscosity conversion method [30]. Furthermore, the relationship between equivalent viscosity and temperature was fitted according to Equation (4). The rutting factor $\left(\mathrm{G}^{*} / \sin \delta\right)$ was used to evaluate the high temperature performance of asphalt binders. The critical temperature is defined as the temperature when the rutting factor is equal to the critical value (i.e., $1.0 \mathrm{kPa}$ for original binder and $2.2 \mathrm{kPa}$ for short-term aged binder). The higher the critical temperature, the better the high temperature performance of the asphalt binder.

$$
\eta=\sin \sigma^{-4.8628} \frac{\left|G^{*}\right|}{\omega}
$$

where,

$\eta=$ equivalent viscosity $(\mathrm{Pa} \cdot \mathrm{s})$,

$\sigma=$ phase angle $\left({ }^{\circ}\right)$,

$\left|G^{*}\right|=$ dynamic shear modulus (Pa),

$\omega=$ angular frequency ( $\mathrm{rad} / \mathrm{s})$.

$$
\lg \lg \left(\eta \times 10^{3}\right)=\mathrm{n}+\operatorname{mlg}(\mathrm{T}+273.13)
$$

where,

$\eta=$ equivalent viscosity $(\mathrm{Pa} \cdot \mathrm{s})$,

$\mathrm{T}=$ Rankine temperature $\left({ }^{\circ} \mathrm{R}\right)$,

$\mathrm{m}, \mathrm{n}=$ dimensionless parameters.

The frequency sweep test was used to analyze the phase structure and master curve of the asphalt binder. The master curve of rheological parameters at the reference temperature was obtained by translating the results of the frequency scanning tests at different temperatures. Therefore, $40{ }^{\circ} \mathrm{C}$ was selected as the reference temperature, and the Christensen-Anderson-Marasteanu (CAM) model 
was used to construct the dynamic shear modulus master curve according to Zeng et al. 2001 [31]. The modified CAM function is shown in Equation (5).

$$
\left|G^{*}\right|=\frac{\left|G^{*}\right|_{g}}{\left[1+\left(\frac{\mathrm{f}_{\mathrm{c}}}{\mathrm{f}}\right)^{\mathrm{k}^{\mathrm{m}_{\mathrm{c}} / \mathrm{k}}}\right.}
$$

where,

$\left|\mathrm{G}^{*}\right|=$ dynamic shear modulus of frequency scanning test $(\mathrm{kPa})$,

$\left|G^{*}\right|_{\mathrm{g}}=$ glass dynamic shear modulus $(\mathrm{kPa})$,

$\mathrm{f}_{\mathrm{C}}=$ location parameter with dimensions of frequency $(\mathrm{Hz})$,

$\mathrm{f}=$ frequency of scanning test $(\mathrm{Hz})$,

$\mathrm{k}, \mathrm{m}_{\mathrm{c}}=$ shape parameters.

\subsection{Low-Temperature Creep Test}

Low-temperature creep tests were conducted at temperatures of -12 and $-18{ }^{\circ} \mathrm{C}$, using a bending beam rheometer (BBR). Prior to the tests, the sample was heated to liquid state, poured into the mold and allowed to cool down to room temperature for about $90 \mathrm{~min}$. The sample was then cooled to around $-5^{\circ} \mathrm{C}$ for $1 \mathrm{~min}$ and demolded. After demolding, the sample beam was submerged in a water bath and kept at a constant test temperature for $60 \mathrm{~min}$. Standard procedure was followed in the test and the deflection of center point was measured continuously. Creep stiffness $(\mathrm{S})$ and creep rate $(\mathrm{m})$ of the sample were calculated. The creep test of bending beams was carried out on both base and biochar modified binders with different aging conditions (short-term and long-term).

\subsection{Fourier-Transform Infrared Spectroscopy Test}

The Fourier-transform infrared spectroscopy (FTIR) test was conducted using a NEXUS 870 spectrometer (Waltham, MA, US). The test was conducted for both base and biochar modified binders. The resolution was $4 \mathrm{~cm}^{-1}$ and spectrum ranged from 4000 to $400 \mathrm{~cm}^{-1}$. The modification mechanism of biochar was studied by analyzing the chemical composition of biochar modified asphalt binder.

\section{Results and Discussion}

\subsection{Physical Properties}

Table 3 presents the mass loss of binders with different biochar contents before and after short-term aging. It can be seen that the mass loss of base asphalt binder was lower than that of biochar modified asphalt binder. The aging process of asphalt binder mainly includes the volatilization of light components and the oxidative aging of components. The volatilization of light components will reduce the mass of the binder, and the oxidative aging process will increase the mass of the binder. The mass loss of biochar modified asphalt binder was higher, which indicates that biochar did not inhibit the volatilization of light components. Walters et al. studied the chemical and physical properties of biochar, and the results show that the presence of carbon could enhance the flow properties of asphalt binder and reduce the oxidation of asphalt binder during aging [16]. Therefore, it is preliminarily concluded that biochar improves the anti-aging properties of asphalt binder mainly by alleviating oxidative aging of asphalt binder components, rather than reducing the volatilization of light components. Another finding is that the mass change peaked at a biochar content of $12.5 \%$, indicating that biochar has limited effect on the binder's anti-aging performance.

Table 4 displays the results of the softening point and penetration tests of base and biochar modified binders after aging. It can be seen that, with the increase in biochar content, the penetration of asphalt binder at $25{ }^{\circ} \mathrm{C}$ decreased and the softening point increased, which indicates increased 
viscosity and improved thermal stability of biochar modified asphalt binder for both the original and aged binders.

Table 3. Mass loss of asphalt binder after aging.

\begin{tabular}{ccccccc}
\hline Biochar Content (\%) & 0 & 5 & 7.5 & 10 & 12.5 & 15 \\
\hline Mass Loss (\%) & 0.02 & 0.035 & 0.069 & 0.056 & 0.127 & 0.060 \\
\hline
\end{tabular}

Table 4. Properties of conventional asphalt binder after short-term aging.

\begin{tabular}{cccccccc}
\hline \multirow{2}{*}{ Property } & \multicolumn{5}{c}{ Biochar Content (\%) } \\
\cline { 3 - 7 } & & $\mathbf{0}$ & $\mathbf{5}$ & $\mathbf{7 . 5}$ & $\mathbf{1 0}$ & $\mathbf{1 2 . 5}$ & $\mathbf{1 5}$ \\
\hline \multirow{2}{*}{ Penetration $\left(\mathbf{2 5}{ }^{\circ} \mathbf{C} \mathbf{~} \mathbf{0 . 1} \mathbf{~ m m}\right)$} & Before aging & 63 & 52 & 49 & 46 & 44 & 40 \\
& After aging & 39.5 & 37.9 & 38.3 & 32.7 & 32.2 & 31.4 \\
Softening Point $\left({ }^{\circ} \mathbf{C}\right)$ & Before aging & 47.5 & 49.5 & 51.5 & 52.0 & 52.5 & 53.0 \\
Residual Penetration ratio $(\mathbf{\%})$ & 53.0 & 54.0 & 53.5 & 54.5 & 55.0 & 55.0 \\
Increment of Softening Point $\left(\mathbf{\Delta} \mathbf{T} /{ }^{\circ} \mathbf{C}\right)$ & 62.70 & 72.88 & 78.16 & 71.08 & 73.18 & 78.50 \\
& 5.5 & 4.5 & 2.5 & 2.5 & 2.5 & 2.0 \\
\hline
\end{tabular}

According to You et al., the penetration ratio of asphalt binder after short-term aging can be used to predict the long-term aging resistance of the asphalt binder [32]. As shown in Table 4, the residual penetration ratio of biochar modified asphalt binder after short-term aging was greater than that of base asphalt binder. This shows that the addition of biochar could reduce the sensitivity of road petroleum asphalt binder to aging and improve the aging resistance of asphalt binder. This could be attributed to the fact that the biochar particles have ionic adsorption characteristics and a porous structure, which can adsorb asphalt binder components and interact with them [33]. To some extent, this characteristic of biochar was the reason that the oxidative aging of asphalt binder components was reduced.

Figure 2 displays the aging index and viscosity ratio of biochar modified asphalt binder with different biochar contents. It can be seen that, after short-term aging, the aging index of biochar modified asphalt binder decreased with an increase in the biochar content. This indicates that the aging of biochar modified asphalt binder was lower than base asphalt binder. According to Zhang et al., this is partially attributed to better adhesion between the biochar and base asphalt binder because of its complex fibrous and porous structure, which decreased the oxidation of asphalt binder [18]. The change in viscosity ratio was similar to that of aging index. The viscosity ratio of biochar modified asphalt binder after aging was smaller than the base asphalt binder. This means, compared with base asphalt binder, the viscosity of biochar modified asphalt binder is less affected by aging.

\subsection{Dynamic Rheological Properties}

\subsubsection{Temperature Scanning Test}

The influence of aging on the rheological behavior of base and biochar modified asphalt binder (biochar 5\%) is shown in Figure 3. In Figure 3a, it can be seen that a constant increase in dynamic shear modulus occurred after short-term and long-term aging. It is evident that the increase in shear modulus after long-term aging was greater than after short-term aging. The phase angle on the contrary decreased after aging, and the decrease was more pronounced in low temperature areas. In Figure $3 b$, for the unaged conditions, the shear modulus of biochar modified asphalt binder was $29-78 \%$ higher than that of base asphalt binder, but the difference in phase angle was less than $1 \%$. The phase angle is generally considered to be more sensitive to the chemical structure of the binder [34], which indicates that no significant chemical reaction occurred between the biochar and asphalt binder, and the mixing was mainly physical blends. Taking the temperature of $52{ }^{\circ} \mathrm{C}$, for example, to analyze the effect of aging on the rheological parameters of asphalt binder. After short-term and long-term aging, the shear 
modulus of base asphalt binder increased by $80.17 \%$ and $465.57 \%$, respectively, and the shear modulus of biochar (5\%) modified asphalt binder increased by $57.44 \%$ and $288.54 \%$, respectively. Biochar reduced the effect of aging on the shear modulus of asphalt binder, which was more obvious in long-term aging. After short-term and long-term aging, the phase angle of base asphalt binder decreased by $3.67 \%$ and $12.11 \%$, respectively, and the phase angle of biochar $(5 \%)$ modified asphalt binder decreased by $5.02 \%$ and $11.58 \%$, respectively. The changes in phase angle of the two asphalt binders were similar. The anti-aging effect of biochar was not clearly reflected by the phase angle parameter.

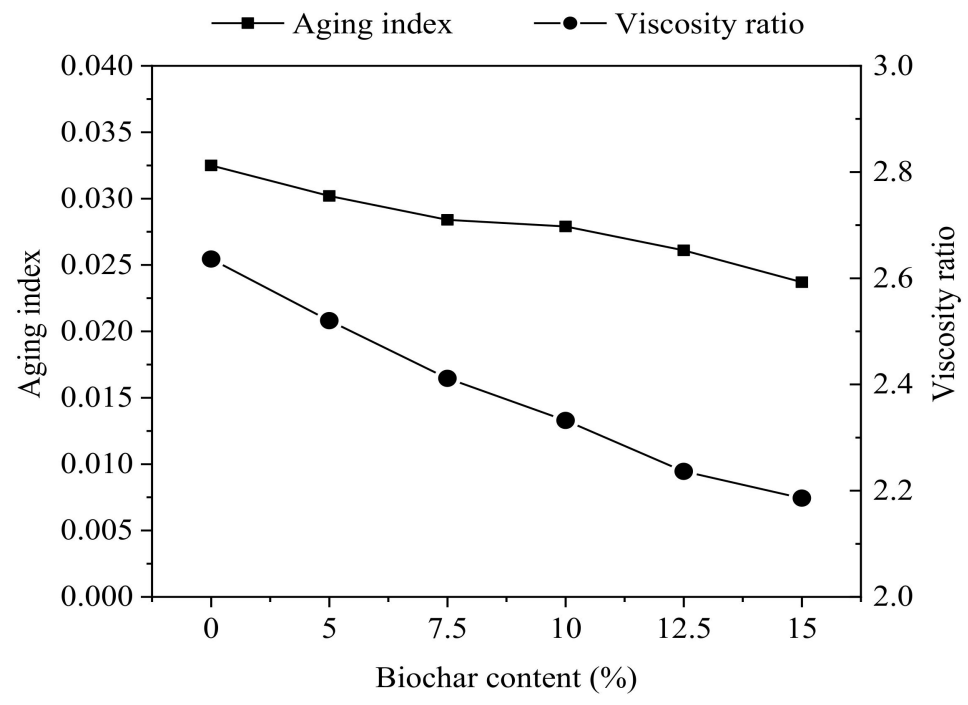

Figure 2. Aging index and viscosity ratio of biochar modified asphalt binder.

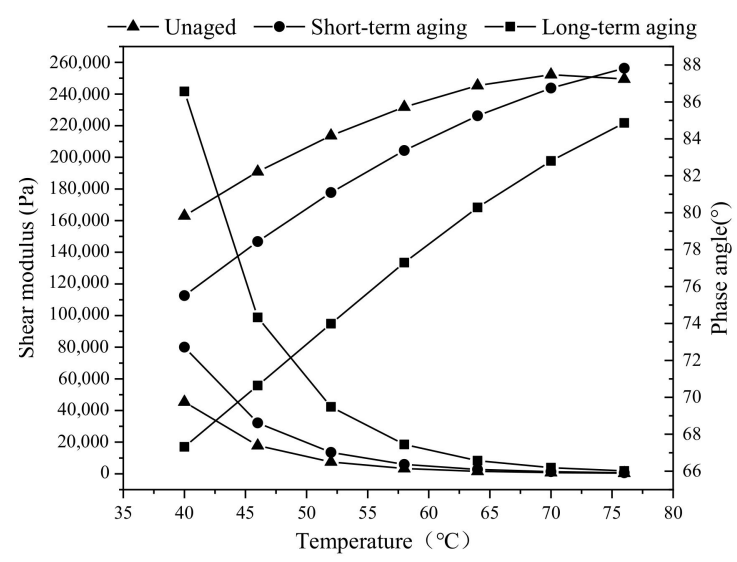

(a) Base asphalt binder

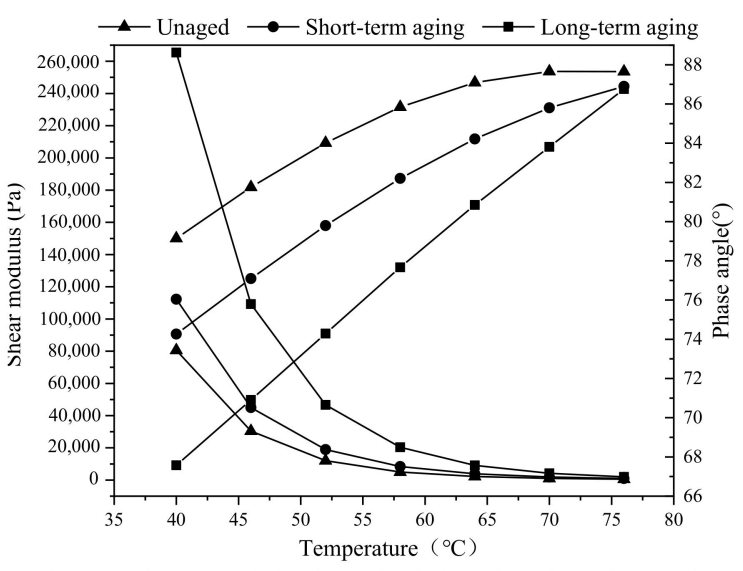

(b) Biochar modified asphalt binder (biochar 5\%)

Figure 3. Effect of ageing on the rheological behavior of asphalt binder.

Figure 4 shows the results of linear fitting of the viscosity and temperature for each asphalt binder after short-term aging. The slope of the fitted curve was VTS. The smaller the VTS, the greater the temperature sensitivity of the asphalt binder. Figure 5 summarizes the VTS of biochar modified asphalt binder in different aging states.

Figure 5 shows the viscosity-temperature susceptibility of biochar modified asphalt binder. As shown, the viscosity-temperature susceptibility increased after short-term and long-term aging, and the biochar content made almost no effect on the increase in viscosity-temperature susceptibility, which indicates that the temperature sensitivity of the asphalt binder was reduced. This could be attributed to the increase in asphaltene content and the decrease in oil content after aging [35-37]. 


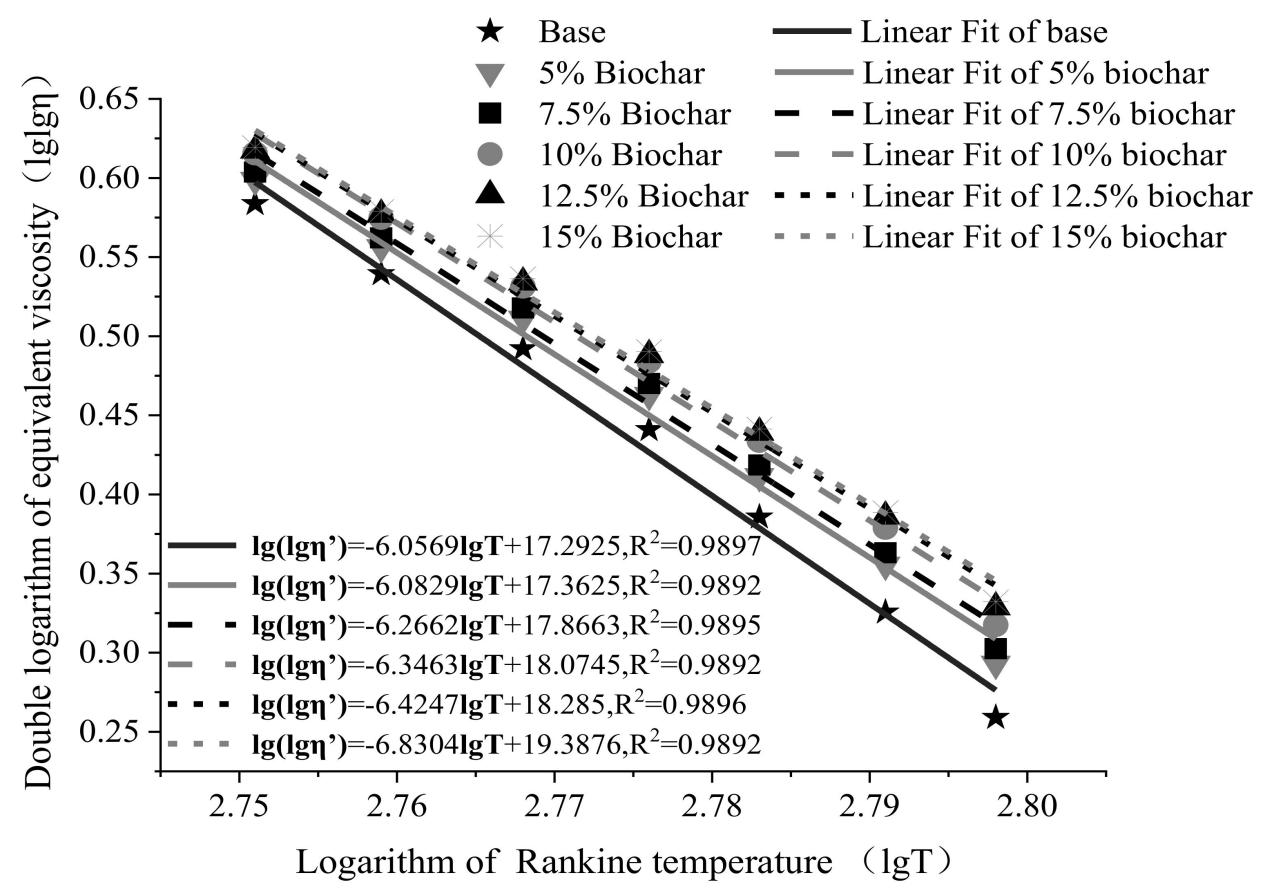

Figure 4. Viscosity-temperature relationship of different asphalt binders after short-term aging.

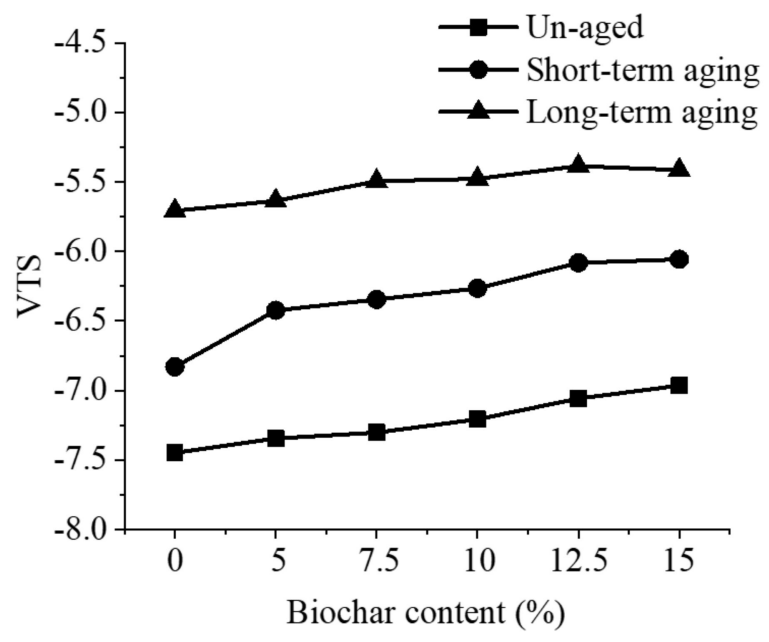

Figure 5. Viscosity-temperature susceptibility (VTS) of biochar modified asphalt binder before and after aging.

Figure 6a provides the rutting factor of unaged binders at different temperatures, and Figure $6 \mathrm{~b}$ plots the exponential regression curves of rutting factor versus temperature for biochar modified asphalt binder after short-term aging. The regression equations provided from top to bottom in Figure 6 in turn corresponded to the curves, i.e., asphalt binder with $0 \%, 5 \%, 7.5 \%, 10 \%, 12.5 \%$ and $15 \%$ biochar content. From the exponential regression curve, the critical temperature of rutting resistance factor can be obtained. This was the temperature when the original asphalt binder had a rutting factor of $\mathrm{G}^{*} /(\sin \delta)=1.0 \mathrm{kPa}$, and the temperature when short-term aged asphalt binder had a rutting factor of $\mathrm{G}^{*} /(\sin \delta)=2.2 \mathrm{kPa}$. Figure $6 \mathrm{c}$ summarizes the results. 


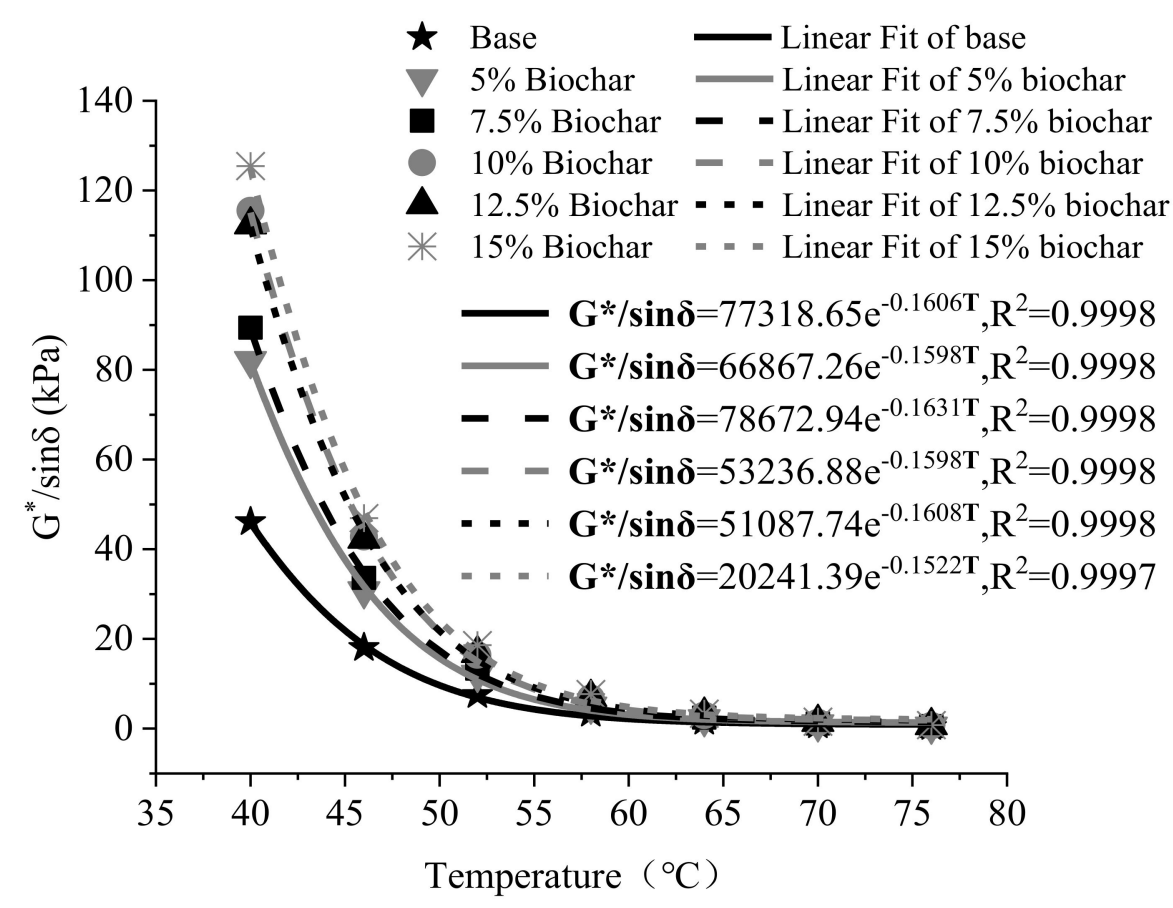

(a) Rutting factors of un-aged asphalt binder

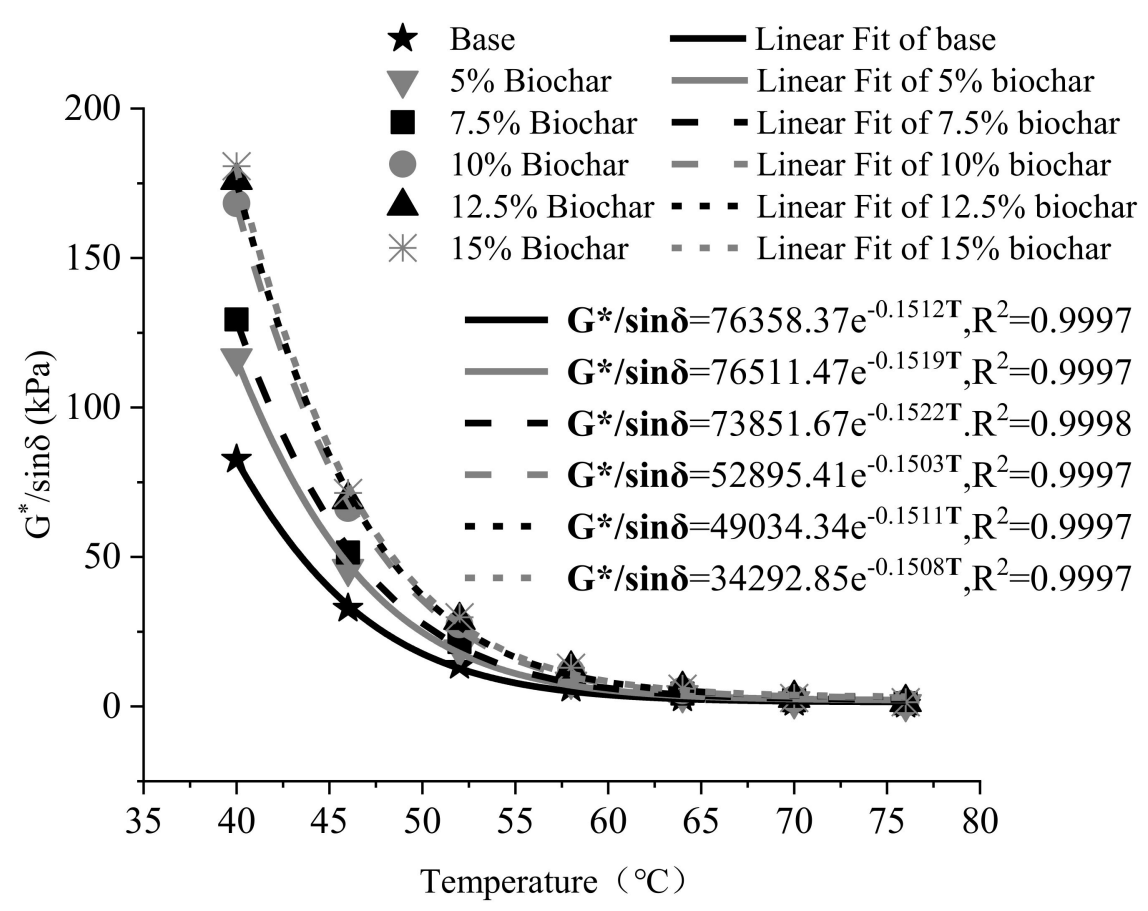

(b) Rutting factors of short-term aged asphalt binder

Figure 6. Cont. 


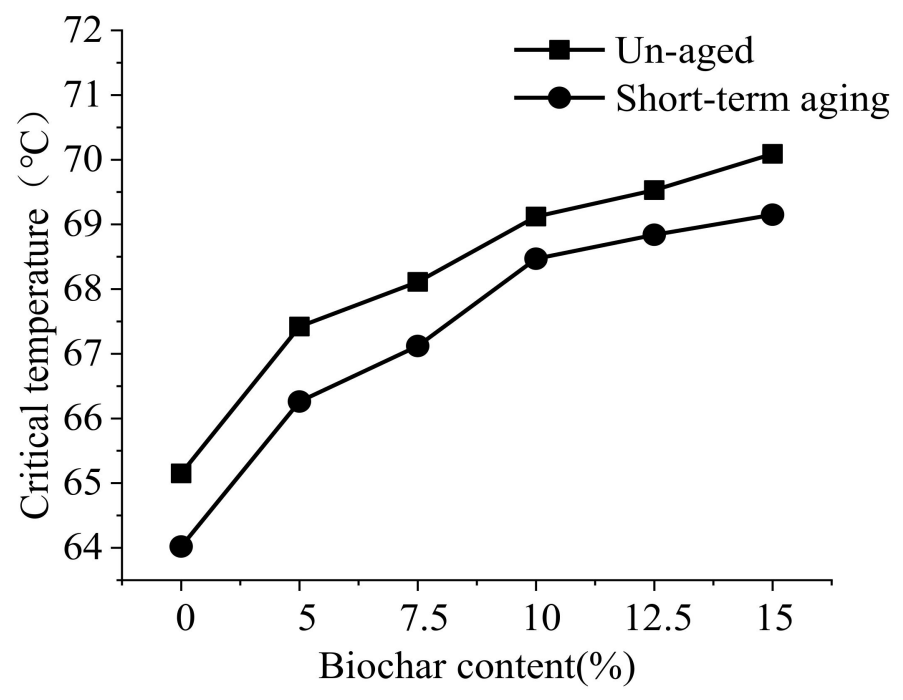

(c) Critical temperatures of rutting resistance factor of asphalt binder

Figure 6. Rutting factors and critical temperatures of asphalt binders under different aging conditions.

As shown in Figure 6a, the rutting factor increased as the amount of biochar increased, which indicates that biochar improves the high temperature performance of asphalt binder. Figure $6 \mathrm{~b}$ showed the same effect for aged asphalt binder. Zhao et al. conducted an asphalt binder pavement analyzer (APA) rutting test on biochar modified asphalt mixture and found that biochar is able to improve rutting resistance [19]. Zhang et al. found that biochar is a mixture of stiff particles with a fibrous and porous structure [18]. As the biochar content increased, the stiff porous particles came into contact with each other, and when the biochar content increased to a higher level, a skeleton could be formed. Biochar could thereby still retain its ability to improve the high temperature performance of asphalt binder after aging.

According to the change rate of rutting factor with temperature before (Figure 6a) and after (Figure $6 \mathrm{~b}$ ) aging, the sooner the rutting factor changed to the critical value after aging, the lower the critical temperature. It can be seen from Figure $6 \mathrm{c}$ that the high-temperature performance of biochar modified asphalt binder increased as a result of adding biochar. The critical temperature of biochar modified asphalt binder increased with the increase in biochar content after aging. Compared to the critical temperatures of unaged asphalt binder, the critical temperatures of biochar modified asphalt binder declined significantly after aging.

\subsubsection{Frequency Scanning Test}

Figure 7 illustrates the results of elastic modulus $\left(G^{\prime}\right)$ and viscous modulus $\left(G^{\prime \prime}\right)$ of biochar modified asphalt binder according to DSR tests at $60^{\circ} \mathrm{C}$. 


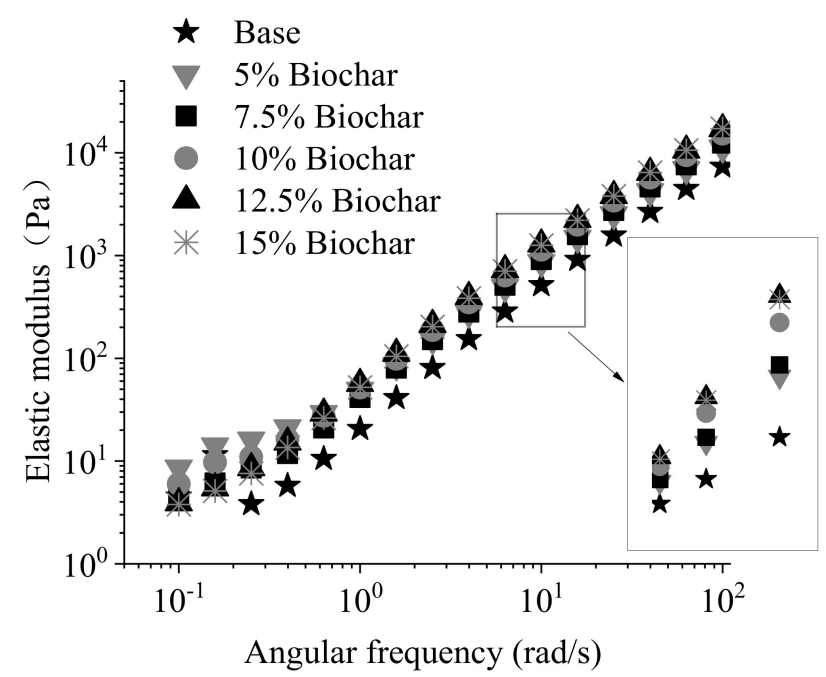

(a) Elastic modulus after short-term aging

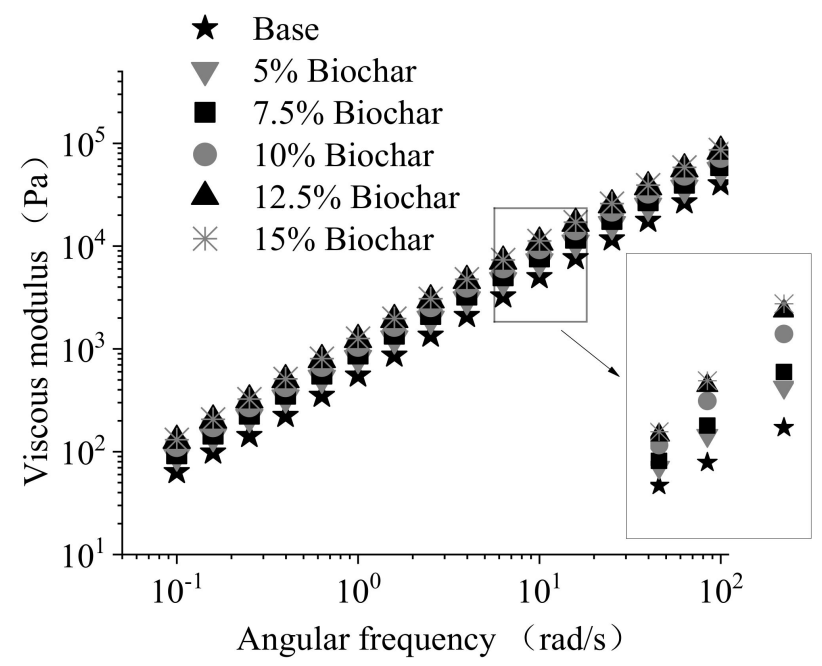

(b) Viscous modulus after short-term aging

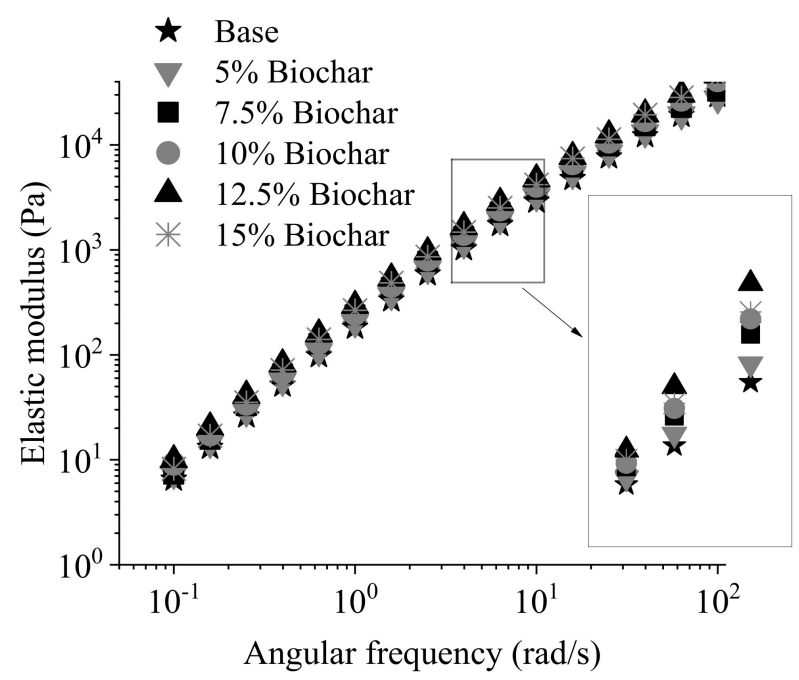

(c) Elastic modulus after long-term aging

Figure 7. Cont. 


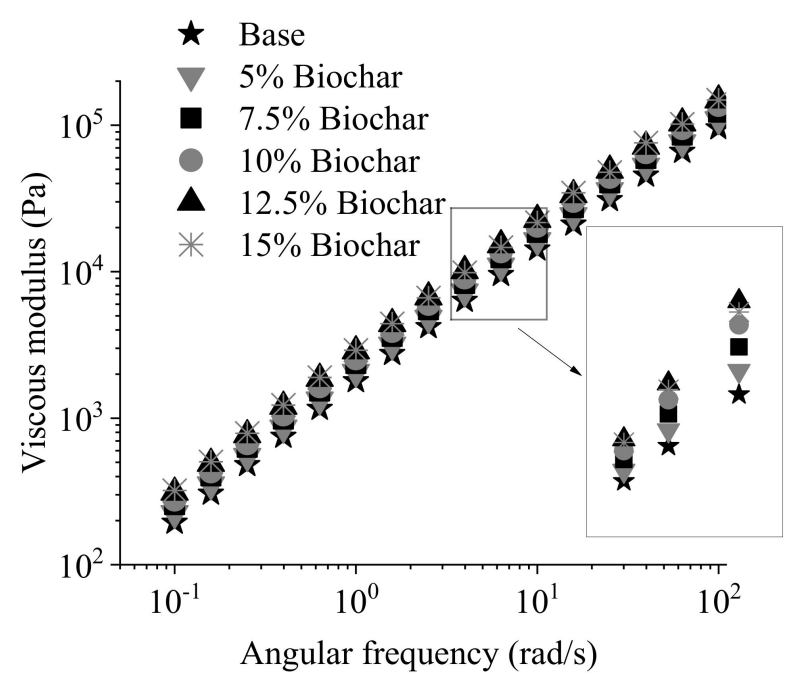

(d) Viscous modulus after long-term aging

Figure 7. Influence of loading frequency on dynamic shear modulus of binder under different aging conditions.

As shown, the modulus and angular frequency were approximately in a linear relationship in the double logarithmic coordinates. The slope of the linear equation was used by He et al. to evaluate the phase structure of asphalt binder. They found that for homogeneous polymers, the theoretical slopes of elastic modulus and viscous modulus are two and one, respectively, and the greater the deviation between the slope of asphalt binder and the slope of homogeneous polymer, the less homogeneous the asphalt binder [38]. The rutting factor $\mathrm{G}^{*} / \sin \delta=1 \mathrm{kPa}$ was used as a screening criterion in the same method. Table 5 summarizes the results. This shows that the slope of dynamic shear modulus and the angular frequency of base asphalt binder and biochar modified asphalt binder decreased after aging, compared with the original asphalt binder. It indicates that the homogeneity of biochar modified asphalt binder was less than the base asphalt binder, which means the biochar particles changed the colloidal structure of asphalt binder by adsorbing asphalt binder components and interacting with them. This interaction between biochar and asphalt binder components alleviated oxidative aging of asphalt binder components. This is consistent with the findings by others [18].

Table 5. Slope of dynamic shear modulus and frequency curve of asphalt binder before and after aging.

\begin{tabular}{|c|c|c|c|c|c|c|c|}
\hline Item & Modulus & Base & 5\% Biochar & 7.5\% Biochar & $10 \%$ Biochar & 12.5\% Biochar & 15\% Biochar \\
\hline \multirow{2}{*}{ Un-Aged } & $\mathrm{G}^{\prime}(\mathrm{Pa})$ & 1.20 & 1.25 & 1.23 & 1.24 & 1.24 & 1.24 \\
\hline & $\mathrm{G}^{\prime \prime}(\mathrm{Pa})$ & 0.93 & 0.93 & 0.94 & 0.93 & 0.93 & 0.93 \\
\hline \multirow{2}{*}{ Short-Term Aging } & $\mathrm{G}^{\prime}(\mathrm{Pa})$ & 1.20 & 1.16 & 1.19 & 1.19 & 1.19 & 1.19 \\
\hline & $\mathrm{G}^{\prime \prime}(\mathrm{Pa})$ & 0.92 & 0.91 & 0.91 & 0.91 & 0.90 & 0.91 \\
\hline \multirow{2}{*}{ Long-Term Aging } & $\mathrm{G}^{\prime}(\mathrm{Pa})$ & 1.06 & 1.02 & 1.02 & 1.06 & 1.05 & 1.05 \\
\hline & $\mathrm{G}^{\prime \prime}(\mathrm{Pa})$ & 0.87 & 0.86 & 0.87 & 0.86 & 0.86 & 0.86 \\
\hline
\end{tabular}

The dynamic shear modulus master curve of base asphalt binder and biochar modified asphalt binder are shown in Figure 8. It can be seen in Figure 8a that for unaged and short-term aged asphalt binder, the CAM model can well characterize the main curve, but the fitting accuracy of the CAM curve decreases for long-term aged asphalt binder, especially in the low-frequency zone. Whether the CAM model can accurately characterize the rheological properties of asphalt binder after long-term aging is worth further study in the future. In the high-frequency zone, the shear modulus of asphalt binder in different aging states are fairly close. As the frequency decreases, the effect of aging on the shear modulus becomes more obvious, which indicates that the effect of aging on the rheological characteristics of asphalt binder was limited in the low-frequency zone. In Figure 8b, the main curve of 
biochar modified asphalt binder was similar to that of base asphalt binder, but the main curve after long-term aging was closer to the unaged curve, which indicates that biochar alleviated the effect of aging on the rheological behavior of asphalt binder.

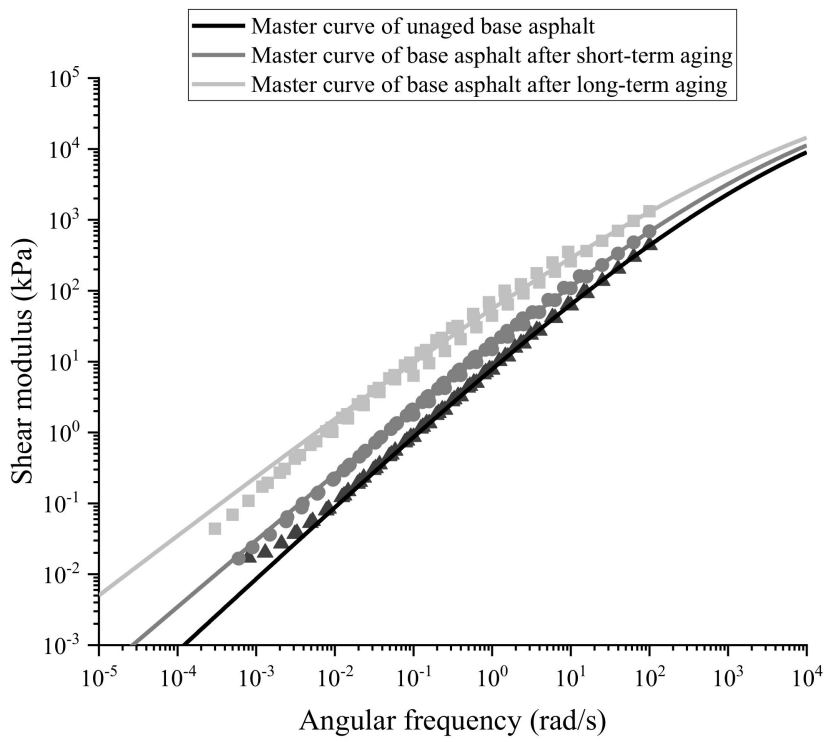

(a) Base asphalt binder

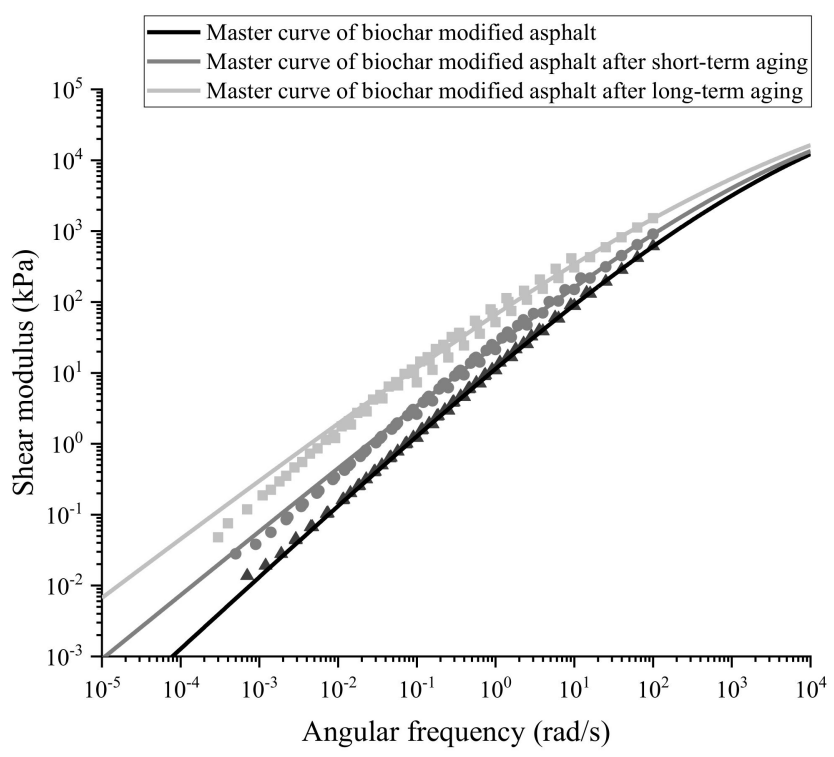

(b) Biochar modified asphalt binder (biochar 5\%)

Figure 8. Dynamic shear modulus master curve of asphalt binder.

\subsection{Low Temperature Performance}

Figure 9 plots the BBR test results of biochar modified asphalt binder under different aging periods at $-12^{\circ} \mathrm{C}$ as an example. The low temperature thermal cracking performance of asphalt mixture is related to the creep stiffness and the slope of creep stiffness versus time curve of the asphalt binder. 


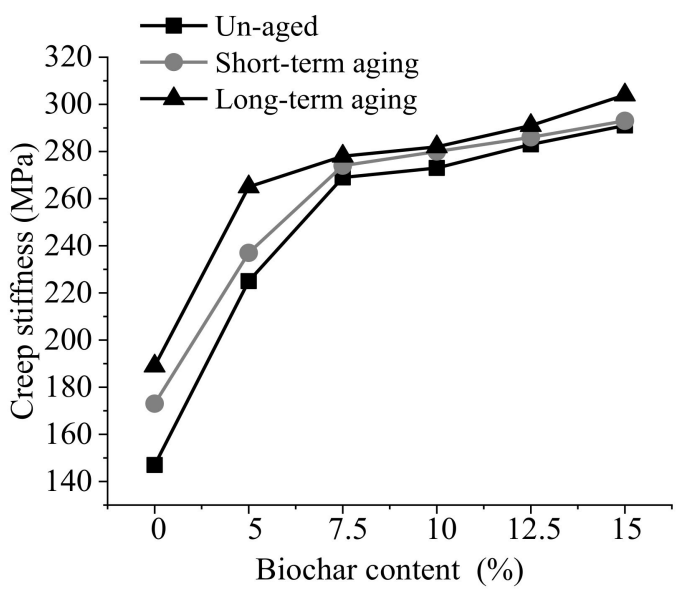

(a) Creep stiffness (S)

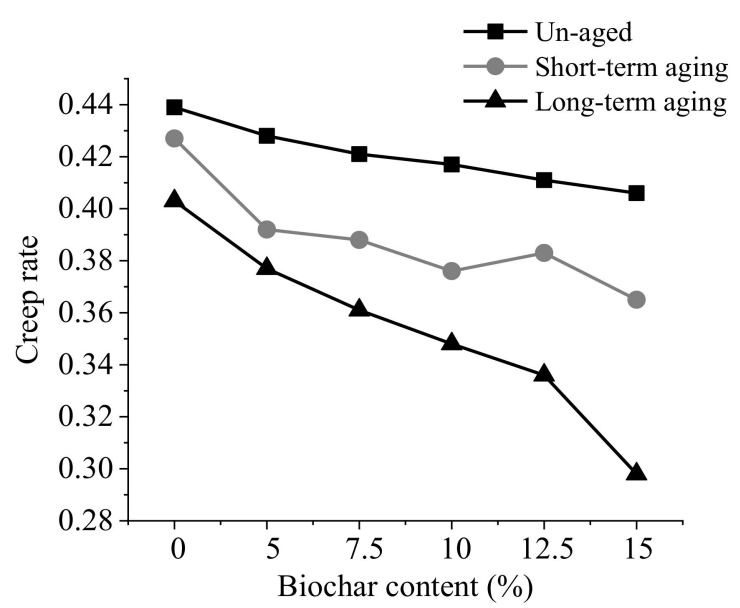

(b) Creep rate $(\mathrm{m})$

Figure 9. Bending beam rheometer (BBR) results under different aging conditions.

As shown in Figure 9a,b, the creep stiffness (S) of base and biochar modified binders increased after aging, and the creep rate $(\mathrm{m})$ decreased after aging. This indicates that aging enhanced the cohesion of asphalt mixture and weakened the flexibility of asphalt binder under load. The greater extent the asphalt binder is aged, the higher the stiffness and the lower the flexibility, indicating a deterioration of low temperature performance.

Figure 10 plots the BBR test results of biochar modified asphalt binder after long-term aging at different temperatures. As it shows, with the increase in biochar content and the decrease in test temperature, the creep stiffness of biochar modified asphalt binder shows an upward trend, while the creep rate shows a downward trend. This indicates that the low temperature performance of biochar modified asphalt binder was compromised with an increase in biochar content.

Adding biochar to asphalt binder could reduce the low temperature performance of asphalt binder, although the reduction was not significant. The low temperature grade of base asphalt binder was $-22{ }^{\circ} \mathrm{C}$, and biochar modified binders with biochar content of $5 \%, 7.5 \%, 10 \%$ and $12.5 \%$ had the same low temperature grade $\left(-22^{\circ} \mathrm{C}\right)$. However, when the biochar content reached $15 \%$, the low-temperature grade of asphalt binder changed from -22 to $-16^{\circ} \mathrm{C}$, indicating a degradation of the low-temperature performance. It is therefore necessary to control the biochar content within $12.5 \%$ in order to maintain the low-temperature grade and low-temperature performance of the modified asphalt binder. 


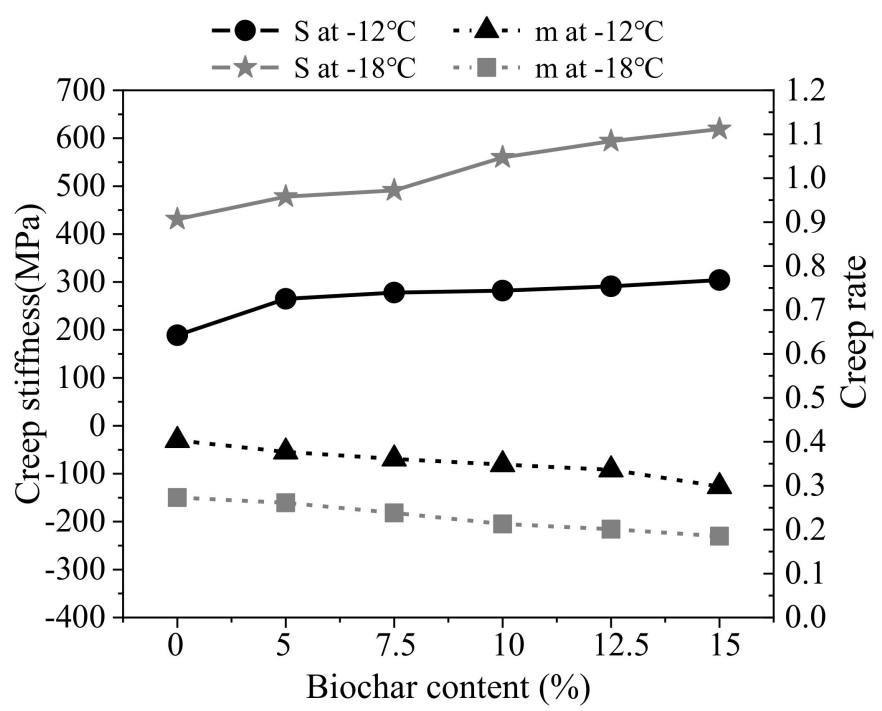

Figure 10. BBR results of biochar modified asphalt binder after long-term aging.

\subsection{FTIR Analysis}

Figure 11 displays the infrared spectrum of biochar, base asphalt binder and biochar modified binders (take $5 \%$ biochar modified asphalt binder as an example). Figure 11a shows that the most obvious absorption peaks of biochar were observed at 3440, 2920, 1640, 1100, 793 and $467 \mathrm{~cm}^{-1}$. The peaks at $3440 \mathrm{~cm}^{-1}$ were attributed to stretching vibrations in hydroxyl. The small peaks at 2930 and $1640 \mathrm{~cm}^{-1}$ were corresponding to methylene and aromatic aldehyde, respectively. The peak of ester carbonyl and peak of aromatic ring were observed at 1100 and $793 \mathrm{~cm}^{-1}$. These indicate that the main components of biochar were aromatic rings, alkanes and hydroxyl groups.

Figure $11 \mathrm{~b}$ shows that the five most obvious absorption peaks occurred at 2920, 2850, 1600, 1460 and $1380 \mathrm{~cm}^{-1}$. In terms of the absorption peak strength, the content of the methylene $\left(-\mathrm{CH}_{2}-\right)$ group in base asphalt binder was higher than that of $\mathrm{CH}_{3}-$ group. This indicates that there were a lot of long chain alkanes in the base asphalt binder. The absorption peak strength at $2720 \mathrm{~cm}^{-1}$ was low, which was the stretching vibration frequency of aliphatic aldehyde-based $\mathrm{CH}$. It can be concluded that the main components of base asphalt binder were long chain alkanes, hydrocarbon derivatives and aromatic compounds. Among them, methylene $-\mathrm{CH}_{2}$ was the most abundant, followed by methyl $-\mathrm{CH}_{3}$. Figure $11 \mathrm{c}$ indicates that the infrared spectrum of biochar modified asphalt binder was similar to that of base asphalt binder. The absorption peaks on the two curves appeared at almost the same wavenumber $/ \mathrm{cm}^{-1}$. The FTIR spectra of biochar modified asphalt binder did not have an obvious new absorption peak. The main chemical components of biochar modified asphalt binder were also aromatic compounds and hydrocarbon compounds. Therefore, biochar in modified asphalt binder is mainly blended physically with the asphalt binder. This indicates that biochar improved the anti-aging performance of asphalt binder mainly by physical effects rather than chemical reactions. 


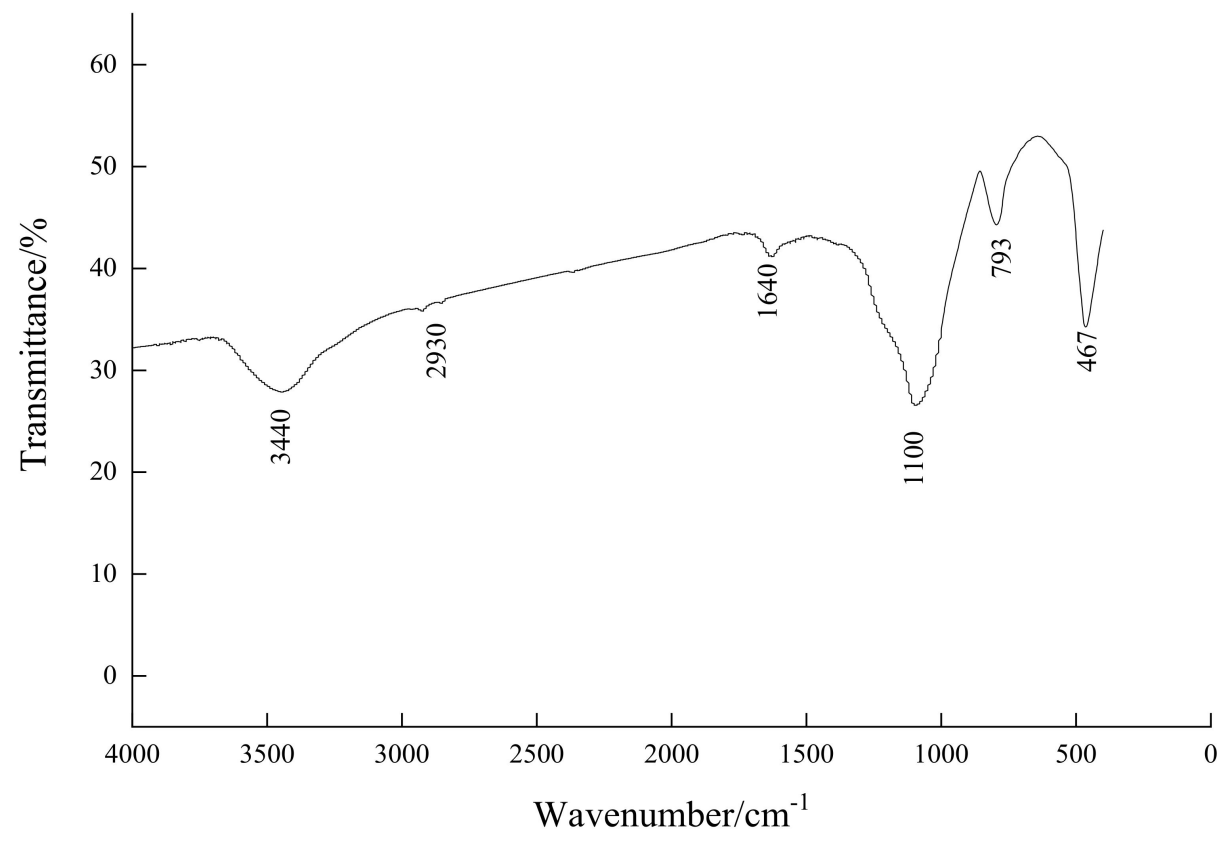

(a) Biochar

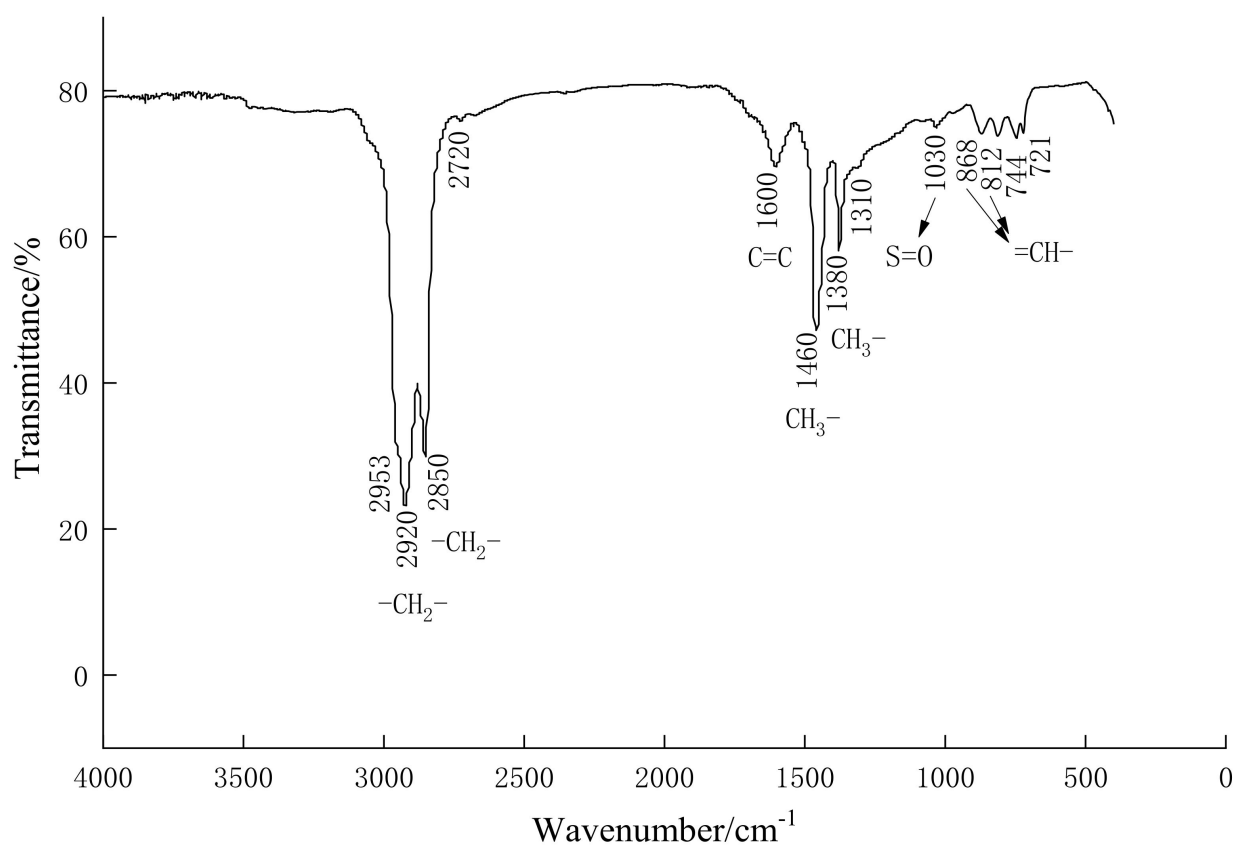

(b) Base asphalt binder

Figure 11. Cont. 


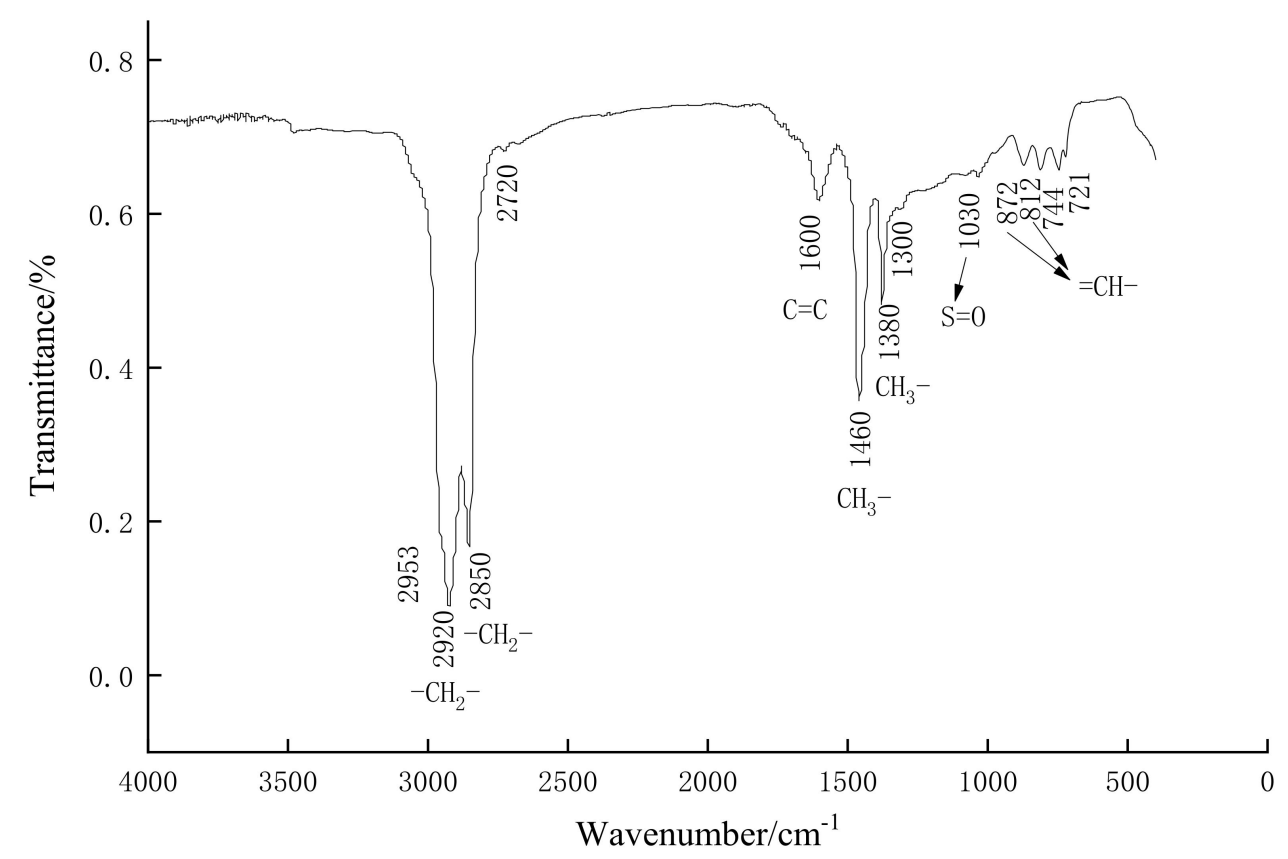

(c) Biochar modified asphalt binder (biochar 5\%)

Figure 11. FTIR spectra of base and modified binders with $5 \%$ biochar.

\section{Conclusions and Recommendations}

Biochar is a renewable biomass resource with potential to improve aging resistance of asphalt binder used in road pavements. In this study, the anti-aging performance of biochar modified asphalt binder was investigated by conducting DSR and BBR tests. Based on the results, the following conclusions can be drawn:

(a) Based on the analysis of aging index and viscosity ratio, the anti-aging performance of biochar modified asphalt binder was better than that of base asphalt binder. The mass loss of biochar modified asphalt binder was higher than base asphalt binder. This indicates that biochar improves the anti-aging properties of asphalt binder mainly by alleviating oxidative aging of asphalt binder components, rather than reducing the volatilization of light components.

(b) When the aging continued, the viscosity-temperature susceptibility of biochar modified asphalt binder increased, and the temperature sensitivity decreased. Biochar adsorbs asphalt binder components because of its porous structure, which reduces the homogeneity of asphalt binder and alleviates oxidative aging of asphalt binder components.

(c) The creep stiffness increased, and creep rate decreased after aging of biochar modified asphalt binder, which indicated that the low temperature performance of biochar modified asphalt binder declined. However, the impact of biochar on low temperature performance of asphalt binder was not significant. When the biochar content reached $15 \%$, the low temperature grade of asphalt binder could not reach $-22{ }^{\circ} \mathrm{C}$. Therefore, the effect on low temperature performance of asphalt binder could be attained by controlling the amount of biochar, which should not exceed $12.5 \%$.

(d) The shapes of the infrared spectrum curves of the base and biochar modified asphalt binder were substantially the same. The main components of biochar were aromatic rings, alkanes and hydroxyl groups. Biochar in modified asphalt binder is mainly blended physically with the asphalt binder.

This paper studied the anti-aging performance of biochar modified asphalt binder from macroscopic indexes. Although all indexes indicate that biochar can improve the anti-aging performance 
of asphalt binder, further studies are needed to identify the level of improvement by different indexes. For example, the FTIR analysis indicated that the biochar in modified asphalt binder was mainly blended physically with the asphalt binder. Future research includes using the microscopic index (carbonyl index) obtained by FTIR to quantify the difference in anti-aging performance of base and biochar modified binders. In the current study, only $5 \%$ biochar was used in the FTIR tests. More contents of biochar can be tested in the future to further verify the conclusion and/or find optimum biochar content for maximizing the enhancement of anti-aging performance.

Author Contributions: Conceptualization, W.D. and F.M.; methodology, F.M.; validation, W.D. and C.L.; formal analysis, W.D.; investigation, Z.F.; data curation, W.D.; writing-original draft preparation, W.D., F.M., and Z.F.; writing-review and editing, Y.H. and J.L.; visualization, C.L.; supervision, Y.H. and J.L. All authors have read and agreed to the published version of the manuscript.

Funding: This research was funded by the Natural Science Found Committee (NSFC) of China (grant no. 51108038 and no. 51108039), and the Special Fund for Basic Scientific Research of Central Colleges, Chang'an University, (grant no. 300102318208).

Conflicts of Interest: The authors declare that they have no conflict of interest.

\section{References}

1. Hamzah, M.O.; Jamshidi, A.; Shahadan, Z. Evaluation of the potential of Sasobit (R) to reduce required heat energy and $\mathrm{CO}_{2}$ emission in the asphalt industry. J. Clean. Prod. 2010, 18, 1859-1865. [CrossRef]

2. Mills-Beale, J.; You, Z. The mechanical properties of asphalt mixtures with Recycled Concrete Aggregates. Constr. Build. Mater. 2010, 24, 230-235. [CrossRef]

3. Boczkaj, G.; Przyjazny, A.; Kamiński, M. Characteristics of volatile organic compounds emission profiles from hot road bitumens. Chemosphere 2014, 107, 23-30. [CrossRef] [PubMed]

4. Zaumanis, M.; Boesiger, L.; Kunz, B.; Cavalli, M.C.; Poulikakos, L. Determining optimum rejuvenator addition location in asphalt production plant. Constr. Build. Mater. 2018, 198, 368-378. [CrossRef]

5. Moralı, U.; Şensöz, S. Pyrolysis of hornbeam shell (Carpinus betulus L.) in a fixed bed reactor: Characterization of bio-oil and bio-char. Fuel 2015, 150, 672-678. [CrossRef]

6. Fu, Z.; Dang, Y.; Guo, B.; Huang, Y. Laboratory investigation on the properties of asphalt mixtures modified with double-adding admixtures and sensitivity analysis. J. Traffic Transp. Eng. (Engl. Ed.) 2016, 5, 30-44. [CrossRef]

7. Fini, E.H.; Al-Qadi, I.L.; You, Z.; Zada, B.; Mills-Beale, J. Partial replacement of asphalt binder with bio-binder: Characterisation and modification. Int. J. Pavement Eng. 2012, 13, 515-522. [CrossRef]

8. Jarecki, M.K.; Parkin, T.B.; Chan, A.S.K.; Hatfield, J.L.; Jones, R. Greenhouse Gas Emissions from Two Soils Receiving Nitrogen Fertilizer and Swine Manure Slurry. J. Environ. Qual. 2008, 37, 1432-1438. [CrossRef]

9. Imam, T.; Capareda, S. Characterization of bio-oil, syn-gas and bio-char from switchgrass pyrolysis at various temperatures. J. Anal. Appl. Pyrolysis 2012, 93, 170-177. [CrossRef]

10. Mohan, D.; Pittman, C.U.; Steele, P.H. Pyrolysis of Wood/Biomass for Bio-oil: A Critical Review. Energy Fuels 2006, 20, 848-889. [CrossRef]

11. Demiral, I.; Ayan, E.A. Pyrolysis of grape bagasse: Effect of pyrolysis conditions on the product yields and characterization of the liquid product. Bioresour. Technol. 2011, 102, 3946-3951. [CrossRef]

12. Cao, X.J.; Liu, P.; Tang, P.M. Review of research progress in Bio-asphalt. Mater. Rep. A 2015, 29, 95-100.

13. Kim, P.; Johnson, A.; Edmunds, C.W.; Radosevich, M.; Vogt, F.; Rials, T.G.; Labbé, N. Surface Functionality and Carbon Structures in Lignocellulosic-Derived Biochars Produced by Fast Pyrolysis. Energy Fuels 2011, 25, 4693-4703. [CrossRef]

14. Choppala, G.K.; Bolan, N.; Megharaj, M.; Chen, Z.; Naidu, R. The Influence of Biochar and Black Carbon on Reduction and Bioavailability of Chromate in Soils. J. Environ. Qual. 2012, 41, 1175-1184. [CrossRef] [PubMed]

15. Abtahi, S.M.; Sheikhzadeh, M.; Hejazi, S.M. Fiber-reinforced asphalt-concrete-A review. Constr. Build. Mater. 2010, 24, 871-877. [CrossRef]

16. Walters, R.C.; Fini, E.H.; Abu-Lebdeh, T. Enhancing asphalt rheological behavior and aging susceptibility using biochar and Nano-clay. Am. J. Eng. Appl. Sci. 2014, 7, 66-76. [CrossRef] 
17. Chebil, S.; Chaala, A.; Roy, C. Use of softwood bark charcoal as a modifier for road bitumen. Fuel 2000, 79, 671-683. [CrossRef]

18. Zhang, R.; Dai, Q.; You, Z.; Wang, H.; Peng, C. Rheological Performance of Bio-Char Modified Asphalt with Different Particle Sizes. Appl. Sci. 2018, 8, 1665. [CrossRef]

19. Zhao, S.; Huang, B.; Shu, X.; Ye, P. Laboratory Investigation of Biochar-Modified Asphalt Mixture. Transp. Res. Rec. J. Transp. Res. Board 2014, 2445, 56-63. [CrossRef]

20. Fu, Z.; Lin, M.L.; Dai, J.S.; Li, X.; Wang, Y.X.; Chen, T.Q. Road performance of biochar modified asphalt. J. Guangxi Univ. (Nat. Sci. Ed.) 2017, 42, 1496-1504.

21. Pinnavaia, T.J.; Chibwe, M.; Constantino, V.R.L.; Yun, S.K. Organic chemical conversions catalyzed by intercalated layered double hydroxides (LDHs). Appl. Clay Sci. 1995, 10, 117-129. [CrossRef]

22. Pan, T. RETRACTED: Coniferyl-alcohol lignin as a bio-antioxidant for petroleum asphalt: A quantum chemistry based atomistic study. Fuel 2013, 113, 454-466. [CrossRef]

23. Ruan, X.; Huang, S.; Chen, H.; Qian, G. Sorption of aqueous organic contaminants onto dodecyl sulfate intercalated magnesium iron layered double hydroxide. Appl. Clay Sci. 2013, 72, 96-103. [CrossRef]

24. He, M.; He, X.J.; Wang, L.J.; Xie, X.L. Flame Retardancy of Polypropelene/LDHs Composites: An Influence of Organo-LDH Types. Adv. Mater. Res. 2013, 815, 478-483. [CrossRef]

25. Li, Y.; Wu, S.; Dai, Y.; Pang, L.; Liu, Q.; Xie, J.; Kong, D. Investigation of sodium stearate organically modified LDHs effect on the anti aging properties of asphalt binder. Constr. Build. Mater. 2018, 172, 509-518. [CrossRef]

26. ASTM D1754/D1754M-09. Standard Test Method for Effects of Heat and Air on Asphaltic Materials (Thin-Film Oven Test); American Society for Testing and Materials: West Conshohocken, PA, USA, 2014.

27. ASTM D6521-13. Standard Practice for Accelerated Aging of Asphalt Binder Using a Pressurized Aging Vessel $(P A V)$; American Society for Testing and Materials: West Conshohocken, PA, USA, 2013.

28. JTG E20-2011. Standard Test Methods of Bitumen and Bituminous Mixtures for Highway Engineering; Ministry of Transport of the People's Republic of China: Beijing, China, 2011.

29. Ma, F.; Ren, X.; Fu, Z. A review of research on bio-asphalt and its road performance. Highw. Eng. 2015, 40, 63-67.

30. Witczak, M.W.; Bari, J. Development of a Master Curve (E*) Database for Lime Modified Asphaltic Mixtures; Arizona State University: Tempe, AZ, USA, 2004.

31. Zeng, M.; Bahia, H.; Zhai, H.; Turner, P. Rheological modeling of modified asphalt binders and mixtures. Assoc. Asph. Paving Technol. 2001, 70, 403-441.

32. You, Z.; Mills-Beale, J.; Fini, E.; Goh, S.W.; Colbert, B. Evaluation of Low-Temperature Binder Properties of Warm-Mix Asphalt, Extracted and Recovered RAP and RAS, and Bioasphalt. J. Mater. Civ. Eng. 2011, 23, 1569-1574. [CrossRef]

33. Walters, R.; Begum, S.A.; Fini, E.H.; Abu-Lebdeh, T. Investigating Bio-Char as Flow Modifier and Water Treatment Agent for Sustainable Pavement Design. Am. J. Eng. Appl. Sci. 2015, 8, 138-146. [CrossRef]

34. Zhang, F.; Yu, J.; Wu, S. Effect of ageing on rheological properties of storage-stable SBS/sulfur-modified asphalts. J. Hazard. Mater. 2010, 182, 507-517. [CrossRef]

35. Zhang, F.; Yu, J.; Han, J. Effects of thermal oxidative ageing on dynamic viscosity, TG/DTG, DTA and FTIR of SBS- and SBS/sulfur-modified asphalts. Constr. Build. Mater. 2011, 25, 129-137. [CrossRef]

36. Yao, H.; You, Z.; Li, L.; Goh, S.W.; Lee, C.H.; Yap, Y.K.; Shi, X. Rheological properties and chemical analysis of nanoclay and carbon microfiber modified asphalt with Fourier transform infrared spectroscopy. Constr. Build. Mater. 2013, 38, 327-337. [CrossRef]

37. Wang, Y.; Sun, L.; Qin, Y. Aging mechanism of SBS modified asphalt based on chemical reaction kinetics. Constr. Build. Mater. 2015, 91,47-56. [CrossRef]

38. He, L.; Wei, J.; Liu, L.; Deng, J. Study on phase structure of rubber asphalt binder based on Han curve. J. Highw. Transp. Res. Dev. 2017, 34, 10-18.

Publisher's Note: MDPI stays neutral with regard to jurisdictional claims in published maps and institutional affiliations. 